\title{
Erratum to: Synthesis, Structural and Magnetic Properties of Polypyrrole Coated $\mathrm{Ni}_{0.2} \mathrm{Ca}_{0.8} \mathrm{Fe}_{2} \mathrm{O}_{4}$ Nanocomposite
}

\author{
Arun S. Prasad · S.N. Dolia · M.S. Dhawan · S. Kumar • \\ V.R. Reddy
}

Published online: 19 July 2013

(C) Springer Science+Business Media New York 2013

Erratum to: J Supercond Nov Magn (2012)

25:1921-1927

DOI 10.1007/s10948-012-1513-5

The original version of this article unfortunately contained mistakes. The values of " $R_{\text {Bragg }}=6.92, \chi^{2}=8.67$ in the text and $\chi^{2}=8.67$ on Fig. 1a", should be written as $R_{\text {Bragg }}=7.23, \chi^{2}=8.79$.

The authors would like to apologize for any inconvenience caused.

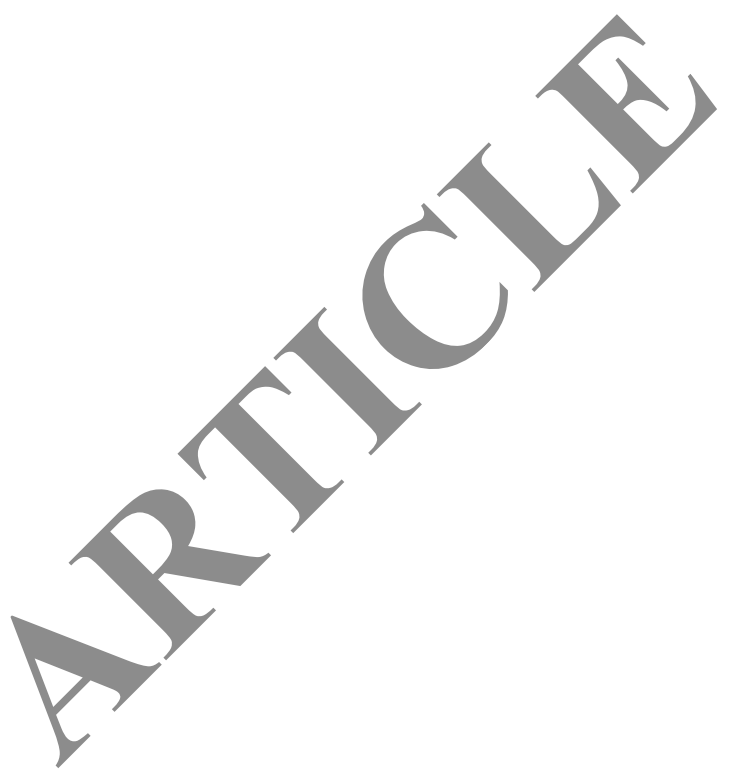

The online version of the original article can be found under doi:10.1007/s10948-012-1513-5.

A.S. Prasad $(\varangle)$

Department of Physics, Arulmigu Meenakshi Amman College of

Engineering, Vadamavandal (Near Kanchipuram),

Tamil Nadu 604 410, India

e-mail: asp.physics@gmail.com

S.N.Dolia-M.S. Dhawan

Department of Physics, University of Rajasthan, Jaipur,

Rajasthan 302 004, India

S. Kumar

Department of Physics, M.L. Sukhadia University, Udaipur,

Rajasthan 313 002, India

V.R. Reddy

UGC-DAE CSR, Khandwa Road, Indore, Madhya

Pradesh 452 017, India 